\title{
MEDICATIONS FOR DISSOLVING THICK MUCUS AND PUS IN THE RESPIRATORY, VISION AND HEARING ORGANS
}

History of discovery of drugs-solvents of thick and viscous pus and other pathological masses.

\author{
1,3A.L. Urakov*, ${ }^{2}$ N.A. Urakova, ${ }^{3}$ L.F. Kartasheva and 3A.P. Stolyarenko
}

\begin{abstract}
'Department of Modeling and Synthesis of Technological Structures Udmurt Federal Research Center of the Ural branch Russian Academy of Sciences, Izhevsk, Russia; 2Department of Obstetrics and Gynecology and 'Department of General and Clinical Pharmacology of the Izhevsk State Medical Academy of the Ministry of health Russian Federation - 426034
\end{abstract}

\section{ABSTRACT}

A review of the scientific and patent literature shows that at the beginning of the $21 \mathrm{st}$ century, a new group of drugs was developed for topical use and related to oxygenalkaline peroxide oxidants. Today, these medications are known as "Pus solvents". They differ from all other drugs in that they have special physical and chemical properties: drugs have a certain alkaline, oxidative, osmotic, temperature activity and contain a gas under high pressure and/or a substance that releases gas. It is shown that drugs of this group are able to quickly dissolve thick and sticky pus, as well as other similar pathological masses: boogers in nose, plaque, tear stones, sulfur plugs, blood clots, spots of dry blood and plasma. It was found that the "necessary" physical and chemical activity is provided by $2-10 \%$ sodium bicarbonate, $0.3-3 \%$ hydrogen peroxide, local hyperthermia $1+39-+42$ ${ }^{\circ} \mathrm{C}$ ) and the dissolution of oxygen, carbon dioxide or inert gas at an excess pressure of 0.2 -4 ATM.

Key words: new drug, thick pus, booger, tear stone, sulfur plug, dry blood. 


\section{Introduction.}

Thick pus, thick mucus, dental plaque and boogers in nose that form in the respiratory tract, tear stones, sulfur plugs that sometimes form in the organs of vision and hearing, as well as blood clots, clots and spots of dry blood that sometimes appear on the surface of the mucous membranes, the surfaces of wounds and on the skin, can be combined in medicine into one group of pathological masses, since they are the same in the nature of its origin and undesirable in these parts of the body. Moreover, all these pathological masses are in the focus of attention of hygienists, who clearly offer to quickly dissolve and remove them in the places of their localization 1-3. At the same time, patients and medical professionals associate success in solving this problem with the use of effective hygiene products. Solutions of antiseptic, disinfecting and chemotherapeutic agents, and sometimes plasma-substituting liquids, are traditionally used as such drugs 4,5 .

However, practice shows that these tools are not able to quickly dissolve thick and viscous pathological masses ${ }^{6-8}$. Therefore, for more reliable and rapid removal of these masses, people use fingers, sticks, matches, toothpicks, brushes and tampons?. At the same time, reference books on medicines and standards for the treatment of diseases do not contain information about special medicines designed for the emergency dissolution of thick pus, thick mucus, dental plaque, tear stones, boogers, sulfur plugs, blood spots and crusts of blood 8 . Therefore, these thick and viscous pathological masses remain for a long time in places that are difficult to access for these mechanical objects, regardless of the drugs used. This conclusion is confirmed by 2 examples in the field of pulmonology: death from hypoxia with accumulation of pus and mucus in the respiratory tract in non-specific pneumonia caused by COVID-19, and months of pus retention in the pleural cavity in tuberculosis empyema of the pleura8,10.

At the beginning of the 21 st century, the situation changed dramatically, because during this period it was shown that thick pus, sulfur plugs, tear stones, blood clots and dry blood crusts can quickly dissolve and discolor with solutions of hydrogen peroxide, if the solutions have special physical and chemical properties 9.11 . In 2008, it was proposed to use an antiseptic solution with increased osmotic activity and an increased content of carbon dioxide. At the same time Russian patents were issued for the following inventions: "Hyper-gassed and hyper-osmotic antiseptic mixture" (RU Patent 2331441) and "Method for peritoneal dialysis using gasified solution" (Ru Patent 2336833).

Then in 2009 a patent was issued in Russia for "Softening agent for thick viscous pusı (RU Patent 2360685). The invented remedy is an aqueous solution of an antiseptic containing 2.7-3.3\% hydrogen peroxide and $5.0-10.0 \%$ sodium hydrocarbonate. This drug was the first alkaline bleach of dense biological masses, since the combination of hydrogen peroxide and sodium bicarbonate was first proposed.

In addition to them the arsenal of solvents thick pus and other similar 
pathological masses includes the following invented drugs and methods of their use:

1. «Method for treating longterm nonhealing woundsı (RU Patent 2187287). The essence of this invention is that the surface of a trophic ulcer is irrigated on the surface of the patient's body with a warm solution of $0.9 \%$ sodium chloride and the wet wound is warmed to a temperature of $+37-+42^{\circ} \mathrm{C}$ later using the Solux lamp.

2. «Method for treating pleural empyema casesı (RU Patent 2308894). The essence of this invention is that a warm solution of an alkaline surfactant with a temperature not exceeding $+42^{\circ} \mathrm{C}$ is injected into the pus and the pus is uniformly moved using a metal rod of a magnetic stirrer under ultrasound control. Moreover, a solution of $24 \%$ eufillin is offered as a medicine with the necessary activity.

3. «Multipurpose solution for epibulbar instillations) (RU Patent 2452478). The essence of this invention is that it is an aqueous solution that contains $\quad 0.55-1.0 \%$ hydrogen peroxide, $1.0 \quad-\quad 1.5 \% \quad$ sodium hydrocarbonate and 0.5-1.0\% lidocaine hydrochloride.

4. «Agent for fistula sanitation in infected pancreonecrosis) (RU Patent 2455010). The essence of this invention is that it is an aqueous solution of $0.9 \%$ sodium chloride, $0.142 \%$ sodium hydrophosphate and $120 \%$ sodium dihydrophosphate at a $\mathrm{pH}=6.7-6.9$ and an osmotic activity of $340-370 \mathrm{mosmol} / \mathrm{l}$ of water.

5. "Uterine lavage technique» (RU Patent 2327471). The essence of this invention is that through a hole in the neck in the area of the bottom of the uterine cavity is introduced heated to a temperature of up to $+42-+45^{\circ} \mathrm{C}$ solution of $0.9 \%$ sodium chloride and $3 \%$ hydrogen peroxide. The solution is introduced until the cavity is completely filled with the foam formed in it. Then a dehydrated silicone gel is introduced into the cavity, impregnated with an equal volume of a solution of $3 \%$ hydrogen peroxide.

6. «Method and means for removal of sulphur plug» (RU 2468776). The essence of the new medicine is that it is a solution of 0.3-0.5\% hydrogen peroxide and 1.7-2.3 \% sodium hydrocarbonate at a temperature of +42 ${ }^{\circ} \mathrm{C}$. The solution is introduced into the sulfur plug by injection until it is completely infiltrated. The novelty of this method lies in the high accuracy provided by injecting the drug solution directly into the sulfur plug. In addition, the new formula provides a moderate "cold boiling" of the solution in the presence of the catalase enzyme and excludes a powerful explosion inside the outer ear cavity.

These innovative medicines and methods of treatment of purulent diseases show that solutions of $0.5-3 \%$ hydrogen peroxide and 1.0-10 \% sodium hydrocarbonate, enriched with carbon dioxide at an excess pressure of 0.2 ATM and heated to $+42^{\circ} \mathrm{C}$ are converted into pus solvents when applied topically. The infusion of such solvents in pus, in a sulfur plug or in similar pathological masses in comparable volumes ensures their complete dissolution to a homogeneous liquid after a few minutes of interaction. 
In parallel, the development of drugs that dissolve and discolor blood clots, dry crusts of blood, blood stains and dental plaque was carried out. In 2009, a Russian patent was issued for «Method of express cleaning of blood stains off clothes») (RU Patent 2371532). The essence of the invention is that for urgent removal and discoloration of blood spots, an aqueous solution of hydrogen peroxide and sodium hydrocarbonate with a $\mathrm{pH}$ of more than 7.0, with an osmotic activity below $140 \mathrm{mosmol} / \mathrm{l}$ of water heated to +42 ${ }^{\circ} \mathrm{C}$. In 2015, a Russian patent was issued for «Bruise bleache» (RU Patent 2539380). The novelty of this tool was the injection of a solution of hydrogen peroxide and sodium hydrocarbonate into the skin in the area of the bruise until creating the effect of "lemon crust" on the entire area of the bruise. Then in 2016, patents were issued for "Bleaching agent" (RU Patent 2589682) and "Agent for intradermal bruise whitening " (RU Patent 2573382) and methods of their application for the purpose of discoloration of the skin in the area of bruises: "Method for skin discoloration in bruising area" (RU Patent 2582215) and "Method for skin discoloration in bruising area" (RU Patent 2586278). In 2017. patents were issued for "Method for emergency bleaching and blood crust removal from skin in place of squeezed out acne» (RU Patent 2631593), «Means for intravital skin whitening near blue eyes» (RU Patent 2639485) and «Method for whitening of bruise under eyel) (RU Patent 2639283). The essence of these inventions is that to discolor the skin in the area of a bruise, it is proposed to apply a tampon to this place, moistened with a warm solution of hydrogen peroxide, sodium hydrocarbonate and a local anesthetic that easily penetrates through the intact skin. In 2018, a patent for the invention was issued "Bleaching opener of dried blood for wrapping bandages adhered to a wound" (RU Patent 2653465). The developed preparation contains $0.75-1 \%$ hydrogen peroxide, $1.2 \%$ sodium hydrocarbonate, $0.5 \%$ lidocaine hydrochloride and bidistilled water. In the same year 2018, a patent was issued for "Decolorant of blood» (RU Patent 2647371). "The drug is intended for washing subcutaneous abscesses, intradermal, subcutaneous hematomas, skin, mucous membranes, surgical materials and clothing, characterized in that it includes at a temperature of +42 ${ }^{\circ} \mathrm{C} \quad 3 \pm 0.3 \%$ hydrogen peroxide and sodium bicarbonate-in an amount that ensures the saturation of the liquid and the retention of sediment at a temperature of $+42{ }^{\circ} \mathrm{C}$."

In 2017, a patent was issued for «Method for whitening of sore under nail» (RU Patent 2631592), in 2018, a patent was issued for «Method for blue nail treatment») (RU Patent 2641386), and in 2019, a patent was issued for «Method of emergency bleaching of skin hematoma under eyell (RU Patent 2679334). The essence of these methods is that used the solution of $3 \%$ hydrogen peroxide and $10 \%$ sodium bicarbonate heated to a temperature of $+37-+42{ }^{\circ} \mathrm{C}$. First, this solution is introduced into the hematoma cavity in a volume that provides discoloration of the tissues, and then this solution is used as a compress.

The analysis of the essence of these solvents of blood clots and the essence of 
these bleachers of blood spots, bruises and hematomas showed that they are all solutions of $0.01-3 \%$ hydrogen peroxide, 1.7 - $10 \%$ sodium hydrocarbonate and $0.125-0.250 \%$ lidocaine hydrochloride heated to $+42^{\circ} \mathrm{C}$.

At the same time, hygiene products were developed to remove plaque from the surface of teeth and dental structures. In 2017, it was invented "Frictional toothpaste") (RU Patent 2626669). The essence of this invention is that as a new paste, a solution of $9.5-10 \%$ sodium bicarbonate and $0.5-1.5 \%$ hydrogen peroxide was proposed, which in a ratio of $5 / 1$ mass is poured into a crystalline sodium bicarbonate.

In 2018, a patent was issued for «Bleaching cleaner of dentures» (RU Patent 2659952). The essence of the invention is that a new bleaching cleaner from dental plaque is offered heated to a temperature of $+37-+42{ }^{\circ} \mathrm{C}$ solution $2.0-$ $10.0 \%$ sodium hydrocarbonate, $3 \pm 0.3 \%$ hydrogen peroxide and gas oxygen at a pressure of 0.2 ATM. It is shown that this product provides cleaning, deodorization, bleaching and disinfection of teeth, dental prostheses and surgical instruments with traces of blood and pus due to hyperthermic softening, alkaline saponification, cavitation loosening, dissolution and oxidative discoloration of various biological masses. It was soon shown that this solution can be enriched with oxygen gas up to 4 ATM. In this case, it can be applied using an irrigator with a more pronounced cleaning effect to clean the surface of teeth, dental constructions and the surface of household ceramic products
Thus, at the beginning of the $21 \mathrm{st}$ century in Russia, several oxygen-alkaline peroxide solvents of thick pus, blood clots and similar thick pathological masses were invented $8,9,11,12$. The main ingredients of this group of products are water, drinking soda (sodium hydrocarbonate) and hydrogen peroxide ${ }^{13,14}$. Local application of pus solvents repeatedly accelerate the dissolution and removal of blood clots, dental plaque, sulfur plugs, boogers, lacrimal stones, as well as thick and sticky pus and mucus from the respiratory, visual and hearing organs, including the pleural cavity in tuberculosis purulent empyema of the pleura 8,15 .

It so happened that, exactly in Russia for the first time was shown the possibility of accelerating and increasing the efficiency of dissolving thick and sticky pus and mucus, lacrimal stones, cerumen, blood clots, plaque, and even milk curds due to such physico-chemical properties of aqueous solutions of various medicines, alkaline, oxidative, osmotic, thermal and gas-forming activity (the ability to shape the process of cold boiling within solutions, and in purulent masses9,11.

At the same time, it was proved that the formulations of a new group of drugs that dilute thick and viscous pathological masses differ from those of all known drugs of other pharmacological groups. The fact is that the new medicines are a warm (at a temperature above $+37^{\circ} \mathrm{C}$ ) solution of sodium bicarbonate (preferably a saturated solution), which contains hydrogen peroxide in a concentration of $0.3-3 \%$ and dissolved gases (carbon dioxide, oxygen or inert 
gases such as helium) under excessive pressure?.

\section{Conclusion}

Thus, such physical and chemical properties of solutions of hydrogen peroxide and sodium bicarbonate, such as alkalinity, hyperthermia and increased gas content under high pressure, make it possible to turn these solutions into bleaching solvents of thick and viscous pathological masses, such as pus, mucus, dental plaque, leeches in the respiratory tract, tear stones and sulfur plugs in the organs of vision and hearing, blood clots, blood spots, crusts of blood and plasma on the surface of wounds, in the area of injuries, bruises and bruises. It has been found that heating solutions of hydrogen peroxide and sodium hydrocarbonate to $+42{ }^{\circ} \mathrm{C}$ and enriching them with gases (carbon dioxide, oxygen or other gases) under excessive pressure can turn them into drugs that quickly dissolve and discolor thick pus, thick mucus, tear stones, sulfur plugs, boogers, blood clots, spots, dry crusts of blood, dental plaque, as well as milk curd and food pollutants on the surface of mucous membranes, skin, teeth, dental prosthetics and ceramic dishes.

Consequently, an important discovery has been made in pharmacy and pharmacology: a group of oxygenalkaline bleaching solvents and bleachers of liquid, thick and solid natural and pathological masses has been discovered. It is established that these drugs urgently dissolve and bleach thick pathological masses due to alkaline saponification and the formation of gas bubbles at cold boiling. In our opinion, they can be attributed to hygienic and / or cosmetic medicines. It is important to emphasize that their use in medicine does not require the permission of Pharmacopoeia committees, since they consist of edible substances and are metabolized to water, carbon dioxide and sodium bicarbonate.

Conflict of interest: None declared.

\section{References}

Collins AD., John EC. "Devices and Methods for Removing Cerumen from an Ear." U.S. Patent Application No. $13 / 928,101$.

Croke LM. "Cerumen Impaction: An Updated Guideline from the AAO-HNSF." American family physician. 2017; 96(4): 263-264.

https://www.aafp.org/afp/2017/0815/p26 3.html.

Samaddar S. et al. Formal education about hygienic aural care and the relationship between aural hygiene awareness and practices: a crosssectional study from a super-speciality hospital in West Bengal, India. International Journal of Community Medicine and Public Health. 2019; 6(8): 3298. doi:10.18203/23946040.ijcmph20193444.

Dy A. E. S., Lapeña Jr J. F. F. External auditory canal dimensions, age, and cerumen retention or impaction in persons with Down syndrome. Annals of Otology, Rhinology \& Laryngology. 2018; 127(4):

253-257. https://journals.sagepub.com/doi/abs/10. $\underline{1177 / 0003489418756678 .}$. 
Griffin J., Anderson E. Compositions and methods for cerumen removal. U.S. Patent No. 10,596,106. 24 Mar. 2020. https://patents.google.com/patent/US10 596106B2/en.

Schwartz S. R. et al. Clinical practice guideline (update): earwax (cerumen impaction). Otolaryngology-Head and Neck Surgery. 2017; 56(1_suppl): 1-29. https://doi.org/10.1177/0194599816671491

Urakov A., Urakova N., Reshetnikov A., Kopylov M., Chernova L. Solvents of pusmedicines with physical-chemical aggressive action. IOP Conf. Series: Journal of Physics: Conf. Series. 2017; 790: 012033. doi:10.1088/17426596/790/1/01203.

Urakov A.L. Pus solvents as new drugs with unique physical and chemical properti. Reviews on Clinical Pharmacology and Drug Therapy. 2019; 17 (4): 89 - 95. doi: 10.17816/RCF17489-95.

Urakov A., Urakova N., Reshetnikov A. Oxygen alkaline dental's cleaners from tooth plaque, food debris, stains of blood and pus: A narrative review of the history of inventions. Journal of International Society of Preventive \& Community Dentistry. 2019; 9 (5): 427-433. doi: 10.4103/jispcd.JISPCD_296_19.

Urakov A.L., Urakova N.A. COVID-19: What drug can be used to treat a new coronavirus disease and why. J. Bio. Innov. 2020; 9(3): 241-251. https://doi.org/10.46344/JBINO.2020.v09i0 3.02 .
Urakov A.L. Creation of "necessary" mixtures of baking soda, hydrogen peroxide and warm water as a strategy for modernization bleaching cleaners of ceramic. Epitőanyag - Journal of Silicate Based and Composite Materials. 2020; 72 (1): 30-35.

doi: https://doi.org/10.14382/epitoanyagjsbcm.2020.6.

Urakov A., Urakova N., Reshetnikov A., Kopylov M., Chernova L. Solvents of pusmedicines with physical-chemical aggressive action. IOP Conf. Series: Journal of Physics: Conf. Series. 2017; 790: 012033. doi:10.1088/17426596/790/1/01203.

\section{Urakov A.L., Urakova N.A., Gadelshina} A.A. New medicines: the bleachers of bruises, blue nails, hematomas, blood stains and bloody crusts. Australasian Medical Journal. 2017;10 (11): 942 - 943.

Urakov A.L. What are bruises ? Causes, Symptoms, Diagnosis, Treatment, Remedies. IP Int J Comprehensive Adv Pharmacol. 2020; 5(1): 1-5. doi: http://doi.org/10.18231/j.ijcaap.2020.001.

\footnotetext{
Urakov A., Urakova N., Chernova L. Possibility of dissolution and removal of thick pus due to the physical-chemical characteristics of the medicines. Journal of Materials Science and Engineering $B$. 2013; 3 (11): $714-720$.
} 